\title{
Mortality risk of bloodstream infection caused by either Escherichia coli or Klebsiella pneumoniae producing extended-spectrum $\beta$-lactamase: a prospective cohort study
}

\author{
Osman Sianipar ${ }^{1 *} \mathbb{C}$, Widya Asmara², Iwan Dwiprahasto ${ }^{3}$ and Budi Mulyono ${ }^{1}$
}

\begin{abstract}
Objective: Several studies reported that infection of extended-spectrum $\beta$ lactamase (ESBL)-producing Escherichia coli (E. coli) or Klebsiella pneumoniae (K. pneumoniae) contributed to higher mortality rates but others found it was not associated with mortality. A prospective cohort study which involved 72 patients was conducted to assess the risk of mortality of bloodstream infection due to ESBL-producing K. pneumoniae or E. coli as compared to those infected by either K. pneumoniae or E. coli which not produce ESBL.

Result: Mortality in the group of patients infected with ESBL-producing bacteria was 30.6\%, whereas in another group which was infected with non ESBL-producing bacteria was $22.2 \%(p=0.59)$. Kaplan-Meier's analysis showed that the survival rate during 14-days follow-up among these two group was not significantly different $(p=0.45)$ with hazard ratio 1.41 (95\% Cl 0.568-3.51). Stratification analysis found that adult and elderly patients, patients with sign of leukocytosis, and patients treated with carbapenem were modifier effect variables.
\end{abstract}

Keywords: Bloodstream infection, K. pneumoniae, E. coli, Extended-spectrum $\beta$-lactamase, Mortality

\section{Introduction}

Bloodstream infection is known as the presence of positive blood culture with clinical signs and symptoms of infection for which contamination can be excluded. Gram negative rod bacteria are frequently found as the cause of infection [1, 2]. Among this group, Escherichia coli (E. coli) and Klebsiella pneumoniae (K. pneumoniae) are the most common bacteria reported as the etiology of bloodstream infection [1-4].

Antimicrobia resistance rates increased worldwide as reported in a recent World Health Organization (WHO) global report on antimicrobial resistance surveillance. $K$. pneumoniae and E. coli were 2 out of 7 species of bacteria

\footnotetext{
*Correspondence: osmansianipar@ugm.ac.id

1 Department of Clinical Pathology and Laboratory Medicine, Faculty of Medicine, Public Health and Nursing, Universitas Gadjah Mada, Radioputro Building 5th Floor, Jalan Farmako, Sekip Utara, Yogyakarta, Indonesia

Full list of author information is available at the end of the article
}

in which antimicrobial resistance was surveyed [5]. These 2 clinical isolates could produce extended-spectrum $\beta$ lactamase (ESBL) which could give rise to multi resistant. Recent study reported that the prevalence of ESBLproducing K. pneumoniae and ESBL-producing E. coli in Pekanbaru Indonesia were $66.2 \%$ and $62.2 \%$ respectively [6]. Another study conducted in Banda Aceh, Indonesia reported that prevalence of ESBL-producing $K$. pneumoniae and ESBL-producing E. coli were $80 \%$ and $85 \%$ respectively [7].

Risk of mortality was reported higher among patients who were infected with resistant strains of microbes [5, 8, 9]. Mortality rates of patients infected by ESBL-producing $E$. coli or K. pneumoniae were higher compared to those infected by non ESBL-producing $E$. coli or $K$. pneumoniae [10, 11]. But some studies reported that risk of mortality of patients infected by ESBL-producing $E$. coli/or K. pneumoniae was not statistically different compared with those infected by non ESBL-producing $E$. coli or K. pneumoniae [12-15]. The aim of this study was to 
assess the risk of mortality of bloodstream infection due to ESBL-producing $K$. pneumoniae or E. coli as compared to those infected by either K. pneumoniae or E. coli which not produce ESBL.

\section{Main text Methods}

This was a prospective cohort study that involved 72 patients who suffered from bloodstream infection caused by either $E$. coli or $K$. pneumoniae with Pitt bacteremia score less than 4 . This score was measured according to previous study [10]. The subject of the study were recruited consecutively up to number of sample in each group were sufficient. One group consisted of 36 subjects infected by ESBL-producing E. coli or K. pneumoniae (exposed group), whereas another group consisted of 36 subjects infected by non ESBL- producing E. coli or $K$. pneumoniae (un-exposed group). These 2 groups were observed prospectively for 14 days starting right after diagnosis was determined based on positive blood culture to assess patient survived or died during this period. Mortality was defined as the suspension or cessation of vital processes of the body, as heart beat and respiration. Exposure was bloodstream infection caused by ESBL-producing E. coli or K. pneumoniae. It was determined whenever one set blood culture ( 2 bottles) gave consistent result of bacterial growth of either E. coli or $K$. pneumoniae. Identification of these isolates and also ESBL-producing bacteria was done by microdilution broth method using Vitek 2 system.

Blood samples were inoculated into 2 bottles aerobic blood culture media (ratio sample: media approximately 1:10), and then incubated in an automatic incubator. After the growth of bacteria was detected, samples were further processed for gram staining and microscopic examination as well as sub-cultured onto McConkey and blood agar media. Identification and antimicrobial susceptibility tests were conducted from the colony that grew on these 2 media. Identification of isolates were performed using the Vitek 2 system.

Source of laboratory data were from both Clinical laboratory of Dr. Sardjito and Panti Rapih Hospitals. Whereas source of clinical data was from both Medical Record Unit of Dr. Sardjito and Panti Rapih Hospitals. A clinical research form was used to collect data from each subject of study.

Sample size was calculated based on mortality of patients suffer from bloodstream infection caused by ESBL-non producing E. coli or K. pneumoniae 15\%. Risk of death among those suffer from bloodstream infection caused by ESBL producing E. coli or K. pneumoniae 3 times. We considered power of the study $80 \%$, confidence interval of $95 \%$, and $10 \%$ drop out. Finally we defined number of subject in each group (expose and unexposed) was 36 subject.

Data collected were analyzed by descriptive statistics. Difference in mean and proportion among exposed and un-exposed group were tested using independent $t$ test and Chi square test respectively. Survival analysis was conducted using Kaplan-Meier analysis in order to analyze probability of surviving in 14 days of both exposed and un-exposed group. Stratification analysis was conducted using Mantel Haenzel test to identify modifier effect variable.

\section{Results}

\section{Characteristics of study subjects}

Subjects of this study consisted of 44 males and 28 females. The clinical diagnosis/condition of the study subjects as the reason for blood culture was mostly suspected sepsis. Among those infected by the ESBL producing bacteria $63.9 \%$ were diagnosed as sepsis, $13.9 \%$ each were diagnosed as SIRS and other infections, and 8.3\% suffered from fever. Meanwhile among those infected by ESBL non-producing bacteria, $36.1 \%$ were diagnosed as sepsis and other infections, $19.4 \%$ diagnosed as systemic inflammatory response syndrom (SIRS), and $8.3 \%$ were diagnosed as fever.

The underlying diseases or comorbidities among study subjects were mostly due to malignant disease, and chronic illness, or malignant disease and chronic diseases. Among those infected with the ESBL producing bacteria, $27.8 \%$ suffered from malignant disease, $16.7 \%$ each suffered from chronic illness, and congenital disease, $8.3 \%$ each suffered from cholestasis, and malignant disease mixed with chronic diseases. Meanwhile the underlying disease/comorbidity among those infected by the ESBL non-producing bacteria were as follows: $33.3 \%$ suffered from malignant disease, $22.2 \%$ suffered from chronic disease, $13.9 \%$ suffered from malignant disease and chronic diseases, $8.3 \%$ suffered from chronic and endocrine diseases, and $5.6 \%$ suffered from cholestasis. The underlying disease/comorbidity which was categorized as other diseases accounted for 19.4\% among those infected by the ESBL producing bacteria, and 11.1\% among those infected by ESBL non-producing bacteria (Table 1).

During 14 days follow-up, after bloodstream infection caused by either E. coli/K. pneumoniae was determined, 53 subjects remained alive, while 19 subjects died (26.4\%). The mortality among those infected by the ESBL producing bacteria was 11 subjects $(30.6 \%)$, while mortality among those infected by ESBL non-producing bacteria was 8 patients $(22.2 \%)$. The proportion of death among these 2 group was not significantly different $(p=0.59)$. 
Table 1 Comparison between ESBL and non-ESBL producing of E. coli or $K$. pneumoniae based on clinical variables

\begin{tabular}{|c|c|c|c|c|}
\hline \multirow[t]{2}{*}{ No } & \multirow[t]{2}{*}{ Variable } & \multicolumn{2}{|c|}{ Bloodstream infection due to either E. coli or K. pneumoniae } & \multirow[t]{2}{*}{$p$} \\
\hline & & ESBL-producing & Non ESBL-producing & \\
\hline \multirow[t]{7}{*}{1} & Type of ward, n (\%) & & & 0.32 \\
\hline & General & $9(25.0)$ & $12(33.3)$ & \\
\hline & Malignancy & $7(19.4)$ & $12(33.3)$ & \\
\hline & Intensive & $12(33.3)$ & $5(13.9)$ & \\
\hline & Surgery & $3(8.3)$ & $3(8.3)$ & \\
\hline & Infection & $2(5.6)$ & $3(8.3)$ & \\
\hline & Other & $3(8.3)$ & $1(2.8)$ & \\
\hline \multirow[t]{3}{*}{2} & Length of stay (day) & & & 0.85 \\
\hline & Mean & 10.52 & 11.21 & \\
\hline & SD & 15.77 & 15.58 & \\
\hline \multirow[t]{5}{*}{3} & Diagnosis, n (\%) & & & 0.08 \\
\hline & Sepsis & $23(63.9)$ & $13(36.1)$ & \\
\hline & SIRS & $5(13.9)$ & $7(19.4)$ & \\
\hline & Fever & $3(8.3)$ & $3(8.3)$ & \\
\hline & Other infection & $5(13.9)$ & $13(36.1)$ & \\
\hline \multirow[t]{8}{*}{4} & Underlying disease/comorbid, n (\%) & & & 0.09 \\
\hline & Malignant disease & $10(27.8)$ & $12(33.3)$ & \\
\hline & Chronic disease & $6(16.7)$ & $8(22.2)$ & \\
\hline & Malignant and chronic diseases & $3(8.3)$ & $5(13.9)$ & \\
\hline & Chronic and endocrine disease & $0(0)$ & $3(8.3)$ & \\
\hline & Cholestasis & $3(8.3)$ & $2(5.6)$ & \\
\hline & Congenital disease & $6(16.7)$ & $0(0)$ & \\
\hline & Other & $7(19.4)$ & $4(11.1)$ & \\
\hline \multirow[t]{3}{*}{5} & Survival in 14 days, $n$ (\%) & & & 0.59 \\
\hline & Alive & $25(69.4)$ & $28(77.8)$ & \\
\hline & Died & $11(30.6)$ & $8(22.2)$ & \\
\hline \multirow[t]{7}{*}{6} & Source of infection, n (\%) & & & 0.60 \\
\hline & Unknown & $14(38.9)$ & $20(55.6)$ & \\
\hline & Lung & $8(22.2)$ & $4(11.1)$ & \\
\hline & Gastrointestinal tract & $3(8.3)$ & $4(11.1)$ & \\
\hline & Urinary tract & $4(11.1)$ & $3(8.3)$ & \\
\hline & Skin & $3(8.3)$ & $1(2.8)$ & \\
\hline & Other & $4(11.1)$ & $4(11.1)$ & \\
\hline
\end{tabular}

ESBL extended-spectrum $\beta$ lactamase, SD standard deviation, SIRS systemic inflammatory response syndrome

The underlying diseases/comorbidities of 11 cases of death in patients with bloodstream infections due to K. pneumoniae was mostly malignant disease (5 subjects), followed by chronic illness (3 subjects), postoperative complication (1 subject), congenital disease (1 subject), and Human Immunodeficiency Virus (HIV) disease stage $3-$ malnutrition (1 subject). Similarly, the underlying diseases/co-morbidities of 8 cases of death in bloodstream infections due to $E$. coli were mostly malignant disease ( 5 subjects), followed by chronic diseases (3 subjects).

\section{Survival analysis}

Among those who suffered from bloodstream infection caused by the ESBL producing bacteria, mortality was $30.6 \%$ subjects $(11 / 36)$. Whereas mortality among those infected by non ESBL-producing bacteria was $22.2 \%$ $(8 / 36)$.

Kaplan-Meier's survival analysis results (Fig. 1) showed that the survival of these two groups did not differ significantly $(p=0.450)$ with a hazard ratio of 1.41 (95\% confidence interval $=0.57-3.51)$. The results of stratified analysis in those infected by $K$. 

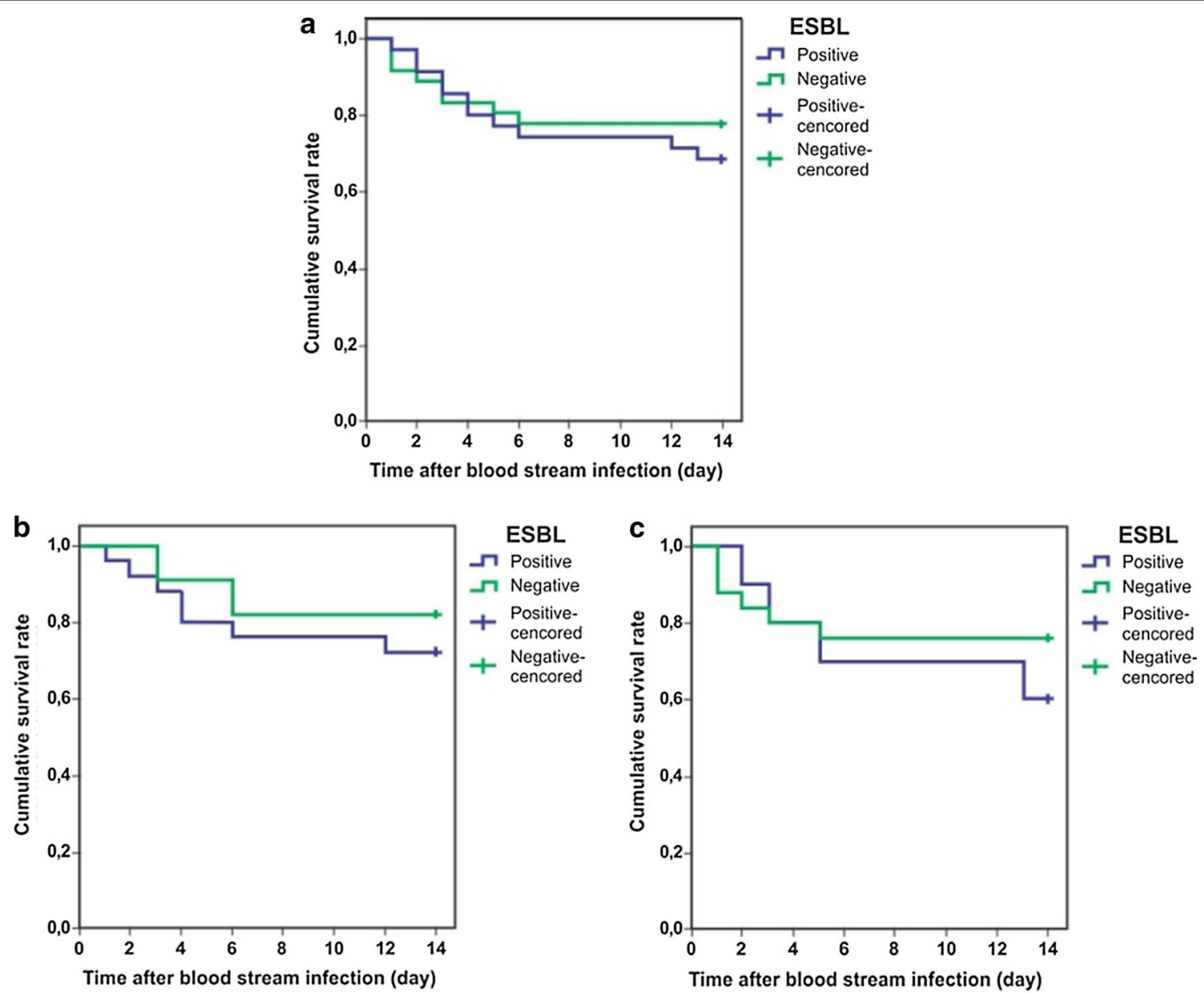

Fig. 1 Survival analysis. a Survival of those infected by either E. coli or K. pneumoniae; b Survival of those infected by K. pneumoniae; c Survival of those infected by E. coli

pneumoniae showed that the survival rate was not significantly different among the patients infected by ESBL producing bacteria, and by ESBL non-producing bacteria $(p=0.53)$. In addition, stratification analysis among those infected by $E$. coli showed a similar result $(p=0.45)$.

\section{Stratification analysis}

This analysis was done in order to identify modifier variables. Eventhough, overall risk of mortality is not different significantly between exposed and un-exposed group but 3 modifier variables could be identified namely those patient with age group adult to elderly, those patient with sign of leukocytosis, and those patient treated with carbapenem. These 3 modifier effect variables were identified if the different between adjusted relative risk $\left(R_{\mathrm{MH}}\right)$ and relative risk crude $\left(\mathrm{RR}_{\text {crude }}\right)$ was at least $10 \%$ [16] (Table 2).

\section{Discussion}

The underlying diseases/comorbidities of the study subjects were mostly malignant disease, and chronic illness, or malignant disease and chronic diseases. Almost all of the study subjects have an underlying disease/comorbidity. This finding is similar to previous studies [8, 17-19].

In this study, overall mortality among exposed group was $26.4 \%$ (19/72). Another similar study reported that 28 day-mortality rate for patients with blood-stream infection was 24.6\% (47/191) [19]. Flokas et al. in 2017 reported that mortality among neonates who suffer from bloodstream infection due to the ESBL producing Enterobacteriaceae was 36\% [20]. In patients suffering from bacteremic pneumonia caused by ESBL-producing $E$. coli or $K$. pneumoniae, 30 day-mortality was reported as $40.5 \%(45 / 111)$ [21].

Mortality of those who suffered from bloodstream infection due to E. coli was $30.8 \%(8 / 26)$. Another similar study reported that 7 days-mortality was $8.5 \%(128 / 1499)$ 
Table 2 Stratification analysis to evaluate mortality risk among those infected by either $E$. coli or $K$. pneumoniae producing ESBL

\begin{tabular}{|c|c|c|c|c|c|}
\hline Strata & $\mathrm{RR}_{\text {Strat }}$ & $95 \% \mathrm{Cl}$ & $p$ & $\mathrm{RR}_{\text {Crude }}$ & $\mathrm{RR}_{\mathrm{MH}}$ \\
\hline Males & 1.89 & $0.59-6.01$ & 0.43 & 1.38 & 1.40 \\
\hline Females & 0.84 & $0.2-3.55$ & 1 & & \\
\hline Neonates up to 17 years old & 0.78 & $0.2-2.98$ & 1 & 1.38 & 1.64 \\
\hline Adult and elderly & 2.57 & $1.04-6.36$ & 0.04 & & \\
\hline Primary bloodstream infection & 1.17 & $0.33-4.10$ & 0.57 & 1.38 & 1.43 \\
\hline Secondary bloodstream infection & 1.65 & $0.61-4.47$ & 0.53 & & \\
\hline Length of stay > 2 days (before bloodstream infection established) & 2.13 & $0.71-6.38$ & 0.29 & 1.38 & 1.25 \\
\hline Length of stay $\leq$ than 2 days (before bloodstream infection established) & 0.62 & $0.21-1.79$ & 0.68 & & \\
\hline Infected by E. coli & 0.96 & $0.29-3.17$ & 0.95 & 1.38 & 1.47 \\
\hline Infected by K. pneumoniae & 2.05 & $0.62-6.76$ & 0.37 & & \\
\hline Leukocytosis & 3.60 & $1.44-9.02$ & 0.01 & 1.38 & 1.68 \\
\hline Non-leukocytosis & 0.52 & $0.13-2.04$ & 0.91 & & \\
\hline Neutropenia & 0.75 & $0.11-5.18$ & 1.00 & 1.38 & 1.45 \\
\hline Non-neutropenia & 1.69 & $0.66-4.34$ & 0.41 & & \\
\hline Underlying disease, malignancies & 1.31 & $0.48-3.58$ & 0.90 & 1.38 & 1.46 \\
\hline Underlying disease, non malignancies & 1.65 & $0.48-5.74$ & 0.48 & & \\
\hline Inappropriate antimicrobial prescription in definitive therapy & 9.53 & $0.60-152.02$ & 0.70 & 1.38 & 1.42 \\
\hline Appropriate antimicrobial prescription in definitive therapy & 0.74 & $0.28-1.93$ & 0.77 & & \\
\hline Definitive therapy using carbapenem & 3.10 & $0.21-46.34$ & 0.29 & 1.38 & 1.63 \\
\hline Definitive therapy using non-carbapenem & 1.25 & $0.49-3.21$ & 0.45 & & \\
\hline Empiric therapy using cephalosporin & 1.10 & $0.39-3.10$ & 1.00 & 1.40 & 1.39 \\
\hline Empiric therapy using non-cephalosporin & 2.08 & $0.51-8.52$ & 0.27 & & \\
\hline
\end{tabular}

$R R_{\text {strat }}$ relative risk from stratification analysis, $R R_{\text {crude }}$ relative risk from total sample, $R R_{M H}$ relative risk from Mantel Haenzel analysis

among those who were infected by E. coli [15]. Thirty days-mortality of this $E$. coli infection was reported as high as $28.5 \%(101 / 354)$ [11]. Number of subject infected by ESBL-producing E. coli was 10 patients, and 3 of them (30.0\%) died during 14 days observation, whereas the mortality among those infected by ESBL non-producing E. coli was $31.25 \%(5 / 16)$. Thirty days-mortality among those infected by ESBL producing E. coli as reported in other study were as follows $26.4 \%(14 / 53)$ [18] and $21.6 \%$ [22]. Another study reported 3 months-mortality as high as $18 \%(34 / 232)$ for older adults and $5.7 \%(7 / 145)$ for younger adults [23].

Mortality of those who suffered from bloodstream infection caused by K. pneumoniae was $23.9 \%$ (11/46). This mortality was lower compared with another study with $46.2 \%$ (48/104) [12]. Twenty-eight days-mortality of bloodstream infection caused by K. pneumoniae was reported in 2 studies as high as $47.9 \%$ (91/190) [24], and $22.8 \%$, respectively [25]. Seven days-mortality of this infection was 9.4\% (33/352) [15]. In this study, mortality among those infected by ESBL producing $K$. pneumoniae and ESBL non-producing $K$. pneumoniae were $30.8 \%(8 / 26)$ and $15.0 \%(3 / 20)$, respectively. Another study reported mortality rates among those infected by
ESBL-producing K. pneumoniae and non ESBL-producing $K$. pneumoniae in an intensive care unit were $9.6 \%$ $(7 / 73)$ and $13.6 \%(3 / 22)$, respectively [26].

In this study risk of mortality among those who suffered from bloodstream infection caused by ESBL producing $E$. coli or $K$. pneumoniae was not significantly different. This result was similar to the finding in another study in which they reported the hazard ratio was 1.65 (95\% CI 0.75-3.64) [14]. In addition, this result was also similar to the findings in 2 other studies $[13,15]$.

Overall risk of mortality among exposed group was not statistically different with those un-exposed group. However, in stratification analysis showed that the exposed group had higher mortality risk as compared to unexposed group especially in adult and elderly patients, patients with sign of leukocytosis, and patients treated with carbapenem. Most probably these 3 modifier effect variables were closely related with more severe clinical condition of the patients. In addition, the relationship between ESBL enzyme and virulence factor needs to be considered. The relationship between these two factors is not yet known with certainty. There are four factors that are suspected to have an effect on the increasing antimicrobial resistance relationship with virulence, namely 
(1) bacterial species; (2) specific virulence and resistance mechanisms; (3) environmental or ecological niche; and (4) the patient (immune system) [27]. Other studies suggest there is no convincing evidence that infections caused by ESBL producing bacteria are associated with poor outcomes (deaths) compared to those caused by non ESBL-producing bacteria, except in cases where antimicrobials were not provided optimally $[9,28]$.

\section{Limitation}

Mortality of patients suffer from bloodstream infection caused by $E$. coli or $K$. pneumoniae might be due to infection of ESBL producing bacteria and also severity of the disease. In this study, severity of bloodstream infection was controlled by Pitt bacteremia score less than 4 for inclusion criteria for inception cohort. Mortality might also be due to progression or severity of underlying disease and/or co-morbid. Unfortunately, we were not able to control severity of these underlying diseases and co-morbid.

\begin{abstract}
Abbreviations
E. coli: Escherichia coli; K. pneumoniae: Klebsiella pneuomiae; ESBL: extendedspectrum $\beta$-lactamase; WHO: World Health Organization; HIV: human immunodeficiency virus; Cl: convidence interval; LOS: length of stay; SIRS: systemic inflammatory response syndrome; SD: standard deviation; $\mathrm{RR}_{\text {strat: }}$ : relative risk from stratification analysis; $R_{\text {crude: }}$ : relative risk from total sample; $R_{M H}$ : relative risk from Mantel-Haenzel analysis; HR: hazard ratio.
\end{abstract}

\section{Acknowledgements}

We would like to thank the Director of Dr. Sardjito Hospital and the Director of Panti Rapih Hospital who have given permission to conduct this study. We also thank the Deans of the Faculty of Medicine, Public Health and Nursing who have supported this research and encouraged this publication. Our gratitude also goes to the Chair of The Department of Clinical Pathology and Laboratory Medicine, to the Chair of Clinical Laboratory of Dr. Sardjito Hospital together with the staffs who supported the study, as well as to the patients who have been willing to participate as research subjects and to all those who have given support to this study.

\section{Authors' contributions}

OS contributed in preparing and implementing the study protocol, preparing the report and manuscript. WA contributed in quality assurance of culture, data analysis, and reviewing the manuscript. ID contributed in research method, data analysis, and reviewing manuscript. BM contributed design and implement study, data analysis, and reviewing manuscript. All authors read and approved the final manuscript.

\section{Funding}

Not applicable

\section{Availability of data and materials}

All data generated or analyzed during this study are included in this published article and additional tables.

\section{Ethics approval and consent to participate}

Medical and Health Research Ethics Committee (MHREC) Faculty of Medicine Gadjah Mada University—Dr. Sardjito Hospital Yogyakarta, Indonesia has approved the protocol as a quality assurance study as stated in Ref: KE/ FK/1140/EC/2016. Written consent had been obtained from all study subjects after sufficient information regarding this study provided.
Consent for publication

Not applicable.

\section{Competing interests}

The authors declare that they have no competing interests.

\section{Author details}

${ }^{1}$ Department of Clinical Pathology and Laboratory Medicine, Faculty of Medicine, Public Health and Nursing, Universitas Gadjah Mada, Radioputro Building 5th Floor, Jalan Farmako, Sekip Utara, Yogyakarta, Indonesia. ${ }^{2}$ Department of Microbiology, Faculty of Veterinary Medicine, Universitas Gadjah Mada, Yogyakarta, Indonesia. ${ }^{3}$ Department of Pharmacology, Faculty of Medicine, Public Health and Nursing, Universitas Gadjah Mada, Radioputro Building 2nd Floor, Jalan Farmako, Sekip Utara, Yogyakarta, Indonesia.

Received: 22 August 2019 Accepted: 18 October 2019

Published online: 01 November 2019

\section{References}

1. Son J, Song J, Ko K, et al. Bloodstream infections and clinical significance of healthcareassociated bacteremia: a multicenter surveillance study in korean hospitals. J Korean Med Sci. 2010;25:992-8.

2. Kanoksil M, Jatapai A, Peacock SJ, Limmathurotsakul D. Epidemiology, microbiology and mortality associated with community-acquired bacteremia in northeast Thailand: a multicenter surveillance study. PLOS ONE. 2013;8:e54714

3. Magret M, Lisboa T, Martin-Loeches I, Máñez R, Nauwynck M, Wrigge H, Cardellino S, Díaz E, Koulenti D, Rello J. Bacteremia is an independent risk factor for mortality in nosocomial pneumonia: a prospective and observational multicenter study. Crit Care. 2011;15:R62.

4. Laupland KB. Incidence of bloodstream infection: a review of populationbased studies. Clin Microbiol Infect. 2013;19:492-500.

5. WHO. Antimicrobial resistance Global Report on Surveillance. New York: WHO; 2014. p. 1-30.

6. Anggraini D, Sholihin UH, Savira M, Djojosugito FA, Irawan D, Rustam RP. Prevalensi dan Pola Sensitivitas Enterobacteriaceae Penghasil ESBL di RSUD Arifin Achmad Pekanbaru. J Kedokt Brawijaya. 2018;30:47.

7. Hayati Z, Rizal S, Putri R. Isolation of extended-spectrum B-lactamase (ESBL) producing Escherichia coli and Klebsiella pneumoniae From Dr. Zainoel Abidin General Hospital, Aceh. Int J Trop Vet Biomed Res. 2019:4:16-22.

8. Ben-David D, Kordevani R, Keller N, Tal I, Marzel A, Gal-Mor O, Maor Y, Rahav G. Outcome of carbapenem resistant Klebsiella pneumoniae bloodstream infections. Clin Microbiol Infect. 2012;18:54-60.

9. Rottier W, Ammerlaan H, Bonten M. Effects of confounders and intermediates on the association of bacteraemia caused by extended-spectrum $\beta$-lactamase-producing enterobacteriaceae and patient outcome: a meta-analysis. J Antimicrob Chemother. 2012;67:1311-20.

10. Paterson DL, Ko W, Von Gottberg A, Mohapatra S, Casellas JM. International prospective study of Klebsiella pneumoniae bacteremia: implications of extended-spectrum $\beta$-lactamase production in. Ann Intern Med. 2004;140:26-32.

11. Melzer M, Petersen I. Mortality following bacteraemic infection caused by extended spectrum beta-lactamase (ESBL) producing E. coli compared to non-ESBL producing E. coli. J Infect. 2007;55:254-9.

12. Tuon F, Kruger M, Terreri M, Penteado-Filho S, Gortz L. Klebsiella ESBL bacteremia-mortality and risk factors. Braz I Infect Dis. 2011;15:594-8.

13. Skippen I, Shemko M, Turton J, Kaufmann M, Palmer C, Shetty N. Epidemiology of infections caused by Escherichia coli and Klebsiella spp.: a nested case e control study from a tertiary hospital in London. J Hosp Infect. 2006:64:115-23.

14. Cordery R, Roberts C, Cooper S, Bellinghan G, Shetty N. Evaluation of risk factors for the acquisition of bloodstream infections with extendedspectrum $\beta$-lactamase-producing Escherichia coli and Klebsiella species in the intensive care unit; antibiotic management and clinical outcome. J Hosp Infect. 2008;68:108-15.

15. Leistner R, Bloch A, Gastmeier P, Schwab F. E. coli bacteremia in comparison to K. pneumoniae bacteremia : influence of pathogen species and 
ESBL production on 7-day mortality. Antimicrob Resist Infect Control. 2016;1:5-8.

16. Maldonado G. Simulation study of confounder-selection strategies. Am J Epidemiol. 1993;138:923-36.

17. Metan G, Zarakolu P, Cakir B, Hascelik G, Uzun O. Clinical outcomes and therapeutic options of bloodstream infections caused by extended-spectrum beta-lactamase-producing Escherichia coli. Int J Antimicrob Agents. 2005;26:254-7.

18. Ha Y, Kang C, Cha M, Park S, Wi Y, Chung D, Peck K, Lee N, Song J. Epidemiology and clinical outcomes of bloodstream infections caused by extended-spectrum $\beta$-lactamase-producing Escherichia coli in patients with cancer. Int J Antimicrob Agents. 2013;42:403-9.

19. Ku N, Kim Y, Kim M, et al. Risk factors for 28-day mortality in elderly patients with extended-spectrum $\beta$-lactamase (ESBL)-producing Escherichia coli and Klebsiella pneumoniae bacteremia. Arch Gerontol Geriatr. 2014:58:105-9.

20. Flokas M, Karanika S, Alevizakos M, Mylonakis E. Prevalence of ESBLproducing enterobacteriaceae in pediatric bloodstream infections : a systematic review and meta- analysis. PLoS One. 2017;1:1-13.

21. Cheng W, Hsueh P, Lee C, Li C, Li M, Chang C, Lee N, Ko W. Bacteremic pneumonia caused by extended-spectrum beta-lactamase-producing Escherichia coli and Klebsiella pneumoniae: appropriateness of empirical treatment matters. J Microbiol Immunol Infect. 2016;49:208-15.

22. To K, Lo W, Chan J, Tse H, Cheng V, Ho P. Clinical outcome of extendedspectrum beta-lactamase-producing Escherichia coli bacteremia in an area with high endemicity. Int J Infect Dis. 2013;17:e120-4.
23. Farooq S, Hayakawa K, Marchaim D, Pogue J, Kaye K. Extended-spectrum B-lactamase-producing Escherichia coli isolation among older adults: epidemiology and outcomes. Am J Infect Control. 2014;42:565-8.

24. Durdu B, Hakyemez I, Bolukcu S, Okay G, Gultepe B, Aslan T. Mortality markers in nosocomial Klebsiella pneumoniae bloodstream infection. Springerplus. 2016;5:1892.

25. Tian L, Tan R, Chen Y, Sun J, Liu J, Qu H, Wang X. Epidemiology of Klebsiella pneumoniae bloodstream infections in a teaching hospital: factors related to the carbapenem resistance and patient mortality. Antimicrob Resist Infect Control. 2016;5:1-12.

26. Nasa P, Juneja D, Singh O, Dang R, Singh A. An observational study on bloodstream extended-spectrum beta-lactamase infection in critical care unit: incidence, risk factors and its impact on outcome. Eur J Intern Med. 2012;23:192-5

27. Beceiro A, Tomás M, Bou G. Antimicrobial resistance and virulence: a successful or deleterious association in the bacterial world? Clin Microbiol Rev. 2013;26:185-230.

28. Schwaber M, Carmeli Y. Mortality and delay in effective therapy associated with extended-spectrum $\beta$-lactamase production in Enterobacteriaceae bacteraemia: a systematic review and meta-analysis. J Antimicrob Chemother. 2007;60:913-20.

\section{Publisher's Note}

Springer Nature remains neutral with regard to jurisdictional claims in published maps and institutional affiliations.
Ready to submit your research? Choose BMC and benefit from:

- fast, convenient online submission

- thorough peer review by experienced researchers in your field

- rapid publication on acceptance

- support for research data, including large and complex data types

- gold Open Access which fosters wider collaboration and increased citations

- maximum visibility for your research: over 100M website views per year

At BMC, research is always in progress.

Learn more biomedcentral.com/submissions 